\title{
Luminescence properties of $\mathrm{KAIP}_{2} \mathrm{O}_{7}$ crystals doped with chromium ions
}

\author{
O.V. Gomenyuk*, S.G. Nedilko, N.V. Stus, O.V. Chukova \\ Kyiv National Taras Schevchenko University, 2, acad. Hlushkov Ave., block 1, 03680 Kyiv, Ukraine
}

\begin{abstract}
Luminescence properties of the $\mathrm{KAlP}_{2} \mathrm{O}_{7}$ crystals doped with the chromium ions were investigated. Luminescence spectra consist of two main bands: one of them lies in the blue-green spectral region and the other lies in the red spectral region. The maximum positions of the bands depend on the crystal composition and temperature of the samples. The blue-green band consists at least of three components. Complex structure of the blue-green broad band results from a superposition of matrix intrinsic radiation and emission of the distorted $\mathrm{CrO}_{4}{ }^{2-}$ groups, where chromium ions have $6+$ ion charge. The red luminescence band and the narrow spectral lines observed for the chromium-doped $\mathrm{KAlP}_{2} \mathrm{O}_{7}$ crystals were assigned to electron transitions in the $\mathrm{Cr}^{3+}$ ions in octahedral oxygen surround. Structure peculiarities of the various types of the chromium luminescence centers formed in the investigated matrix are discussed.
\end{abstract}

Keywords: phosphate, aluminum, chromium, impurity ion, luminescence.

Paper received 19.11.03; accepted for publication 30.03.04.

\section{Introduction}

In spite of the facts that at present a number of materials are used for creation of active bodies for optical solidstate lasers, the necessity to develop new working bodies for such lasers doesn't disappear. There are some main directions for such designs: an intention to get a light generation on the new regions of optics radiations, to get changing of light generation frequency on new diapasons of changing, working out of new sensebilisation schemes of impurity active laser ions. The chromium ions $\mathrm{Cr}^{n+}(n=3$ and 4$)$ draw a great attention in all of these directions that is determined by the set of their physical, chemical and spectral properties [1-3]. High level of the impurity chromium ions concentration can be reached for many oxide compounds without their optical quality to be loosed, therefore those matrixes are in a wide use for the chromium ions doping among of well-known solidstate matrixes. A great number of works is devoted to investigation of spectroscopic (luminescent) properties of such materials doped with the chromium ions, but certain important questions concerning light absorption and emission processes are still uncertified [4-6]. The question about formation of various types luminescence centers are among of them that caused by both possibility for the chromium ions to have get different charges: $\mathrm{Cr}^{3+}, \mathrm{Cr}^{4+}$ and $\mathrm{Cr}^{6+}$ and possibility of various type of chromium ions location in a crystal lattice.

In this paper, the investigation of the double phosphate crystals $\mathrm{KAlP}_{2} \mathrm{O}_{7}$ doped with the chromium ions of different concentrations is carried out. The lattice of these crystals allows an isovalent substitution of the aluminum ions $\mathrm{Al}^{3+}$ of framefork by the chromium impurity ions $\mathrm{Cr}^{3+}$. Besides, as it will be shown later, a principal possibility exists to incorporate the chromium ions in their various charge states into matrix of doubled potassium aluminium phosphate. These properties can be very important for varying the spectral luminescent properties of doped matrix in a wide spectral region.

\section{Experimental methods}

Polycrystalline samples of the $\mathrm{KAlP}_{2} \mathrm{O}_{7}$ crystals were synthesized from a melt of the $\mathrm{K}_{2} \mathrm{O}-\mathrm{Al}_{2} \mathrm{O}_{3}-\mathrm{P}_{2} \mathrm{O}_{5}$ system (qualification of starting reagents was "Chemically Pure" (Ch.P)). Activating chromium ions have been incorporated into samples composition by adding of the $\mathrm{Cr}_{2} \mathrm{O}_{3}$ to the mentioned above system. Concentrations of the $\mathrm{Cr}_{2} \mathrm{O}_{3}$ oxide in the system $C(\mathrm{Cr})$ were $0.02,0.08$ or 1 mass $\%$. Dispersed powders or polycrystalline composites of the $\mathrm{KAlP}_{2} \mathrm{O}_{7}$ were obtained by spontaneous crystallization. 


\section{O.V. Gomenyuk et al.: Luminescence properties of $\mathrm{KAIP}_{2} \mathrm{O}_{7}$ crystals doped with ...}

Luminescence of the $\mathrm{KAlP}_{2} \mathrm{O}_{7}$ crystals was investigated at temperatures $4.2,77$ and $300 \mathrm{~K}$. The samples were placed in helium and nitrogen cryostats in liquid helium and nitrogen when samples temperatures were $4.2 \geq 77 \mathrm{~K}$ respectively. Luminescence spectra were excited by radiation of the ILGI-501 (excitation wavelength $\left.\lambda_{e x}=337.1 \mathrm{~nm}\right), \mathrm{LGN}-503\left(\lambda_{e x}=476.5,488.4\right.$, and $514.2 \mathrm{~nm})$, and LG-22 $\left(\lambda_{e x}=632.8 \mathrm{~nm}\right)$ lasers. Excitation spectra were investigated using radiation of the xenon lamp DXeEl-1000 (excitation wave lengths 300$650 \mathrm{~nm}$ ). Filtration of this radiation was done with double prism spectrometer DMR-4. Spectrometer DFS-12 (reciprocal linear dispersion is $10 \AA / \mathrm{mm}$ ) was used for recording of the luminescence and excitation spectra. Differential reflection spectra (spectra of doped by chromium samples compared to spectra of pure samples) were recorded using the "SPECORD M40" UV VIS spectrometer.

\section{Experimental results}

Doped with chromium the KAlP2O7 (Cr) crystals reveal intensive luminescence practically in all visible region at the excitation by light from the diapason of excitation wavelength $\lambda_{e x}$ (frequency $v_{e x}$ ) 300-650 nm (33000$15400 \mathrm{~cm}^{-1}$ ). Spectra of this emission consist of two bands where one of them ("green-orange" short wave length band) lies in the region $450-690 \mathrm{~nm}$ with the contour maximum of the band $\mathrm{m}$ changed from 495 to $525 \mathrm{~nm}$ and other of them ("red" long wave length band) lies in the region $700-800 \mathrm{~nm}$ with the contour maximum of the band about $\lambda_{m}=740 \ldots 747 \mathrm{~nm}$ at the samples temperatures $T=4.2 \ldots 77 \mathrm{~K}$. The positions of the contour maxima depend on the impurity ions concentration, of the sample temperatures and of excitation wavelengths (Fig. 1, 2).

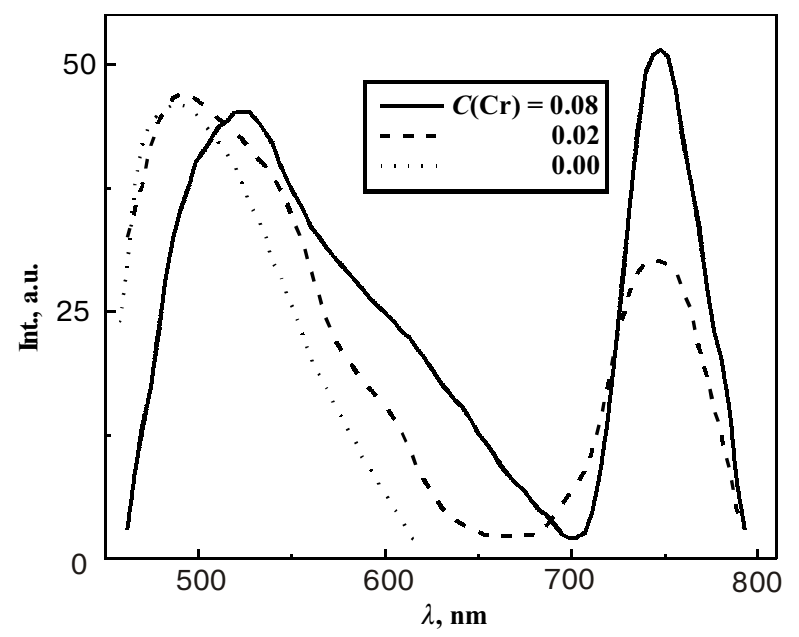

Fig. 1. Luminescence spectra of the $\mathrm{KAlP}_{2} \mathrm{O}_{7}$ crystals pure and doped with chromium ions (Cr) obtained at excitation wave=length $\lambda_{e x}=337.1 \mathrm{~nm}$ and temperature $T=77 \mathrm{~K}$. Chromium ions concentrations are $C(\mathrm{Cr})=0.00$ (pure undoped crystal) 0.02 and 0.08 mass $\%$.

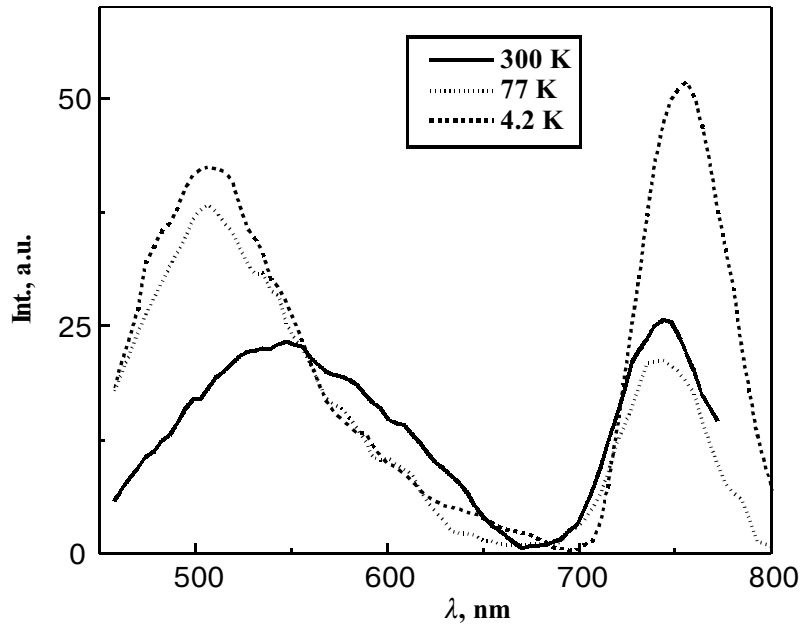

Fig. 2. Luminescence spectra of the $\mathrm{KAlP}_{2} \mathrm{O}_{7}(\mathrm{Cr})$ crystals doped with chromium ions $(C(\mathrm{Cr})=0.02$ mass $\%)$ obtained at excitation wave length $\lambda_{e x}=337.1 \mathrm{~nm}$; and temperatures $T=4.2,77$, and $300 \mathrm{~K}$.

Undoubtedly, the short wave length band consists of several weekly-distinguished structural components. Really, some shoulders and maxima reveal in the structure of band with positions near $\sim 475,505,525,550,600$ and $650 \mathrm{~nm}$ (Fig. 1, 2), and asymmetry of the band shape also confirms this fact. If the chromium content in the samples increases, then the long wave components intensities of the "green-orange" band increase. So, the contour maximum of the band is shifted to the long wave side of the spectra. Relation of the "green-orange" and "red" bands intensities is also changed: relative intensity of the "red" band increases (Fig. 1). Alone short wave length excitation the "green-orange" luminescence band is reveals in the spectra of "pure" undoped crystals where components with peak positions 475 and $505 \mathrm{~nm}$ are predominant. The contour maximum of this band is near $\sim 485$ at $4.2 \mathrm{~K}$ (Fig. 2).

Absolute and relative intensities of the long wave components of the "green-orange" band emission increase at temperature increasing from 4.2 to $300 \mathrm{~K}$ at the short wavelength excitation $\left(\lambda_{e x}=337.1 \mathrm{~nm} v_{e x}=29665 \mathrm{~cm}^{-1}\right)$. The maximum of the band is observed at $\lambda_{m} \cong 545 \mathrm{~nm}$ at $T=$ $=300 \mathrm{~K}$. The relative intensity of the "red" luminescence band increases also if the same changes of temperature take place at the excitation wavelength $\lambda_{e x}=337.1 \mathrm{~nm}$ (Fig. 2).

Therefore, we have many reasons to conclude that "red" luminescence band caused by impurity: it is resulted from electron - vibration radiation transitions in impurity chromium ions. This is confirmed by results of analysis of luminescence excitation spectra and their comparison with the reflection spectra of investigated samples (Fig. 3). It is clear that it will be better to compare the excitation spectra with their absorption spectra, but we have failed to find good absorption spectra as result of the polycrystalline structure of the samples. At the same 


\section{O.V. Gomenyuk et al.: Luminescence properties of $\mathrm{KAIP}_{2} \mathrm{O}_{7}$ crystals doped with ...}

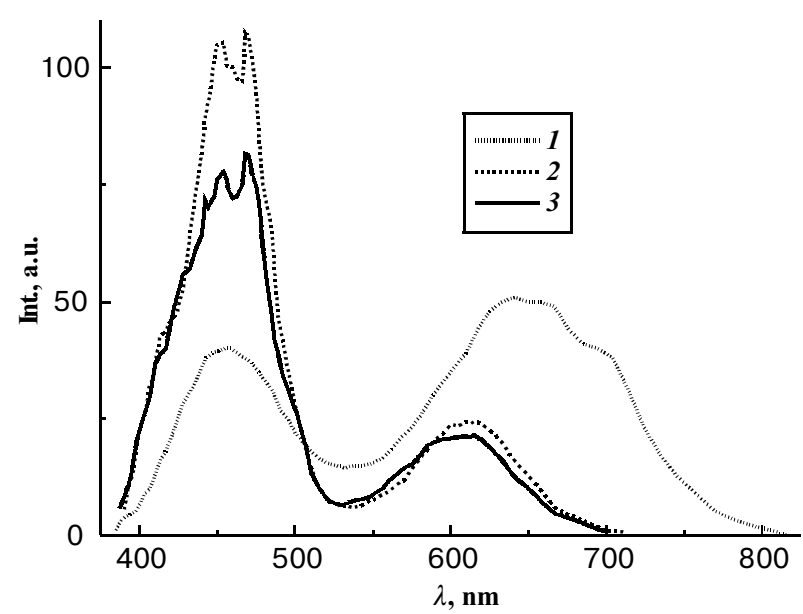

Fig. 3. Reflection (1) and excitation (2, 3) spectra of the $\mathrm{KAlP}_{2} \mathrm{O}_{7}(\mathrm{Cr})$ crystals at $T=300 \mathrm{~K} . \mathrm{C}(\mathrm{Cr})=0.02(2)$ and $0.08(1$, 3) mass $\%$. Registration wavelength is $\lambda_{r}=735 \mathrm{~nm}$

time reflection spectra show the main peculiarities of the absorption spectra. Indeed, one can see on the Fig. 3 two wide bands in the diapasons 530-680 and 380-525 nm both in reflection and spectra of "red" luminescence excitation of the $\mathrm{KAlP}_{2} \mathrm{O}_{7}(\mathrm{Cr}$ ) crystals (they are marked with symbols I and II respectively. The contour maximum of the short wave length one is located at $\lambda_{m}=480 \mathrm{~nm}$. The long wave length band of the reflection spectra is complex, as it reveal at least four peculiarities with maximums positions at $\lambda_{m}=592,638,664$, and $698 \mathrm{~nm}$. It should be noted there is one more band in excitation spectra of the"red" emission (spectral region of $280-350 \mathrm{~nm} ; 35700$ $28600 \mathrm{~cm}^{-1}$ ) with the main maximum at $\lambda_{m} \approx 300 \mathrm{~nm}$. It is possible that it was not registered in the reflection spectra due to its small intensity.

Excitation spectra of the "red" luminescence are similar to the reflection spectra not only by their general view. They are similar in the details of the structure. Really, it is easy to see that maxima and minima in the excitation spectra correspond with the certain peculiarities of the reflection spectra (Fig. 3). Temperature increasing in the region 4.2-300 K doesn't cause any essential changes in the excitation spectra. Influence of temperature is revealed only in the some change of relation of the intensities of the components both of the bands. Particularly, increasing of the relative intensities of the short wave length components of the excitation spectra can be found. Therefore, both types of the spectra have the same nature: they caused by the interaction of the light with impurity chromium ions. We can assume that the main radiation transitions which excite the impurities occur at the wave length (frequencies) those are correspond to the follow maximums $\lambda_{m}\left(v_{m}\right)$ in the excitation spectra: the band III - 300 (33000), 325 (30770), and $340 \mathrm{~nm}$ $\left(29410 \mathrm{~cm}^{-1}\right)$; the band II $-410(24400), 430(23260)$, 455 (21980), 485 (20600), and $510 \mathrm{~nm}\left(19610 \mathrm{~cm}^{-1}\right)$; the band I - 590 (16950), 625 (16000), 645 (15500) and $685 \mathrm{~nm}\left(14600 \mathrm{~cm}^{-1}\right)$.
Then let us observe behavior the luminescence spectra depending on excitation wavelength. As it was mentioned above the excitation in the region of the most short wave length band III of the excitation spectra (the diapason is $280-350 \mathrm{~nm}$ ) initiates both "green-orange" and "red" luminescence bands. Excitation in the region of the middle band II (it is diapason 530-680 nm) initiates the long wavelength components $\left(\lambda_{m}=525,550\right.$ and $600 \mathrm{~nm}$ ) of the "green-orange" and "red" luminescence. At last, the excitation in the region of the most long wave length band I of the excitation spectra (the diapason 530 $680 \mathrm{~nm}$ ) causes only the "red" luminescence (Fig. 4).

The shape of this band depends on the sample temperatures. The band is narrowed when temperature decreases from 300 to $4.2 \mathrm{~K}$ and on the background of its short wave length wing in the region $700-725 \mathrm{~nm}$ some shoulders arise. They can be regarded as revealing of some fine structure details. The last are revealed at $\lambda_{e x}=632.8$ as one sharp peak at $\lambda_{m}=708 \mathrm{~nm}$ and two smaller intensities shoulders located near 704, 712 and 725 nm (Fig. 5).

\section{Discussion}

Described results show that both doped and undoped the $\mathrm{KAlP}_{2} \mathrm{O}_{7}$ crystals reveal luminescent properties. That is why, taking into account obtained experimental data we can assume that luminescence of the doped $\mathrm{KAlP}_{2} \mathrm{O}_{7}(\mathrm{Cr})$ crystals is caused by matrix, which originates own emission and impurity chromium ions those initiate an emission formed by them impurity luminescence centers. The proper "blue-green" radiation can be caused by various reasons. Some of them are conditioned by matrix other one caused by uncontrolled reasons. At present there are not enough experimental data to discuss a nature of this emission. Certain data about both any variants of impu-

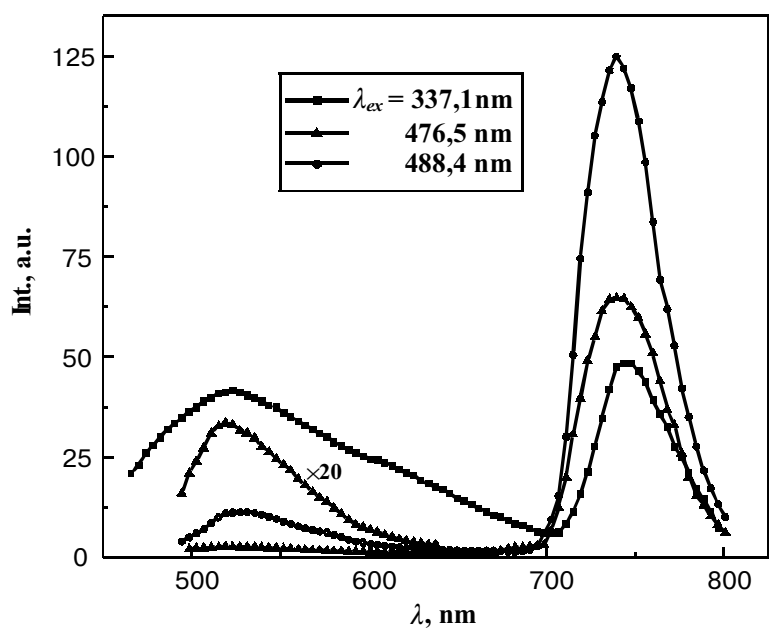

Fig. 4. Luminescence spectra of the $\mathrm{KAlP}_{2} \mathrm{O}_{7}(\mathrm{Cr})$ crystals $(C(\mathrm{Cr})=$ $=0.02$ mass \%) at $T=77 \mathrm{~K} ; \lambda_{e x}=337.1,476.5$ and $488.4 \mathrm{~nm}$. 


\section{O.V. Gomenyuk et al.: Luminescence properties of $\mathrm{KAIP}_{2} \mathrm{O}_{7}$ crystals doped with ...}

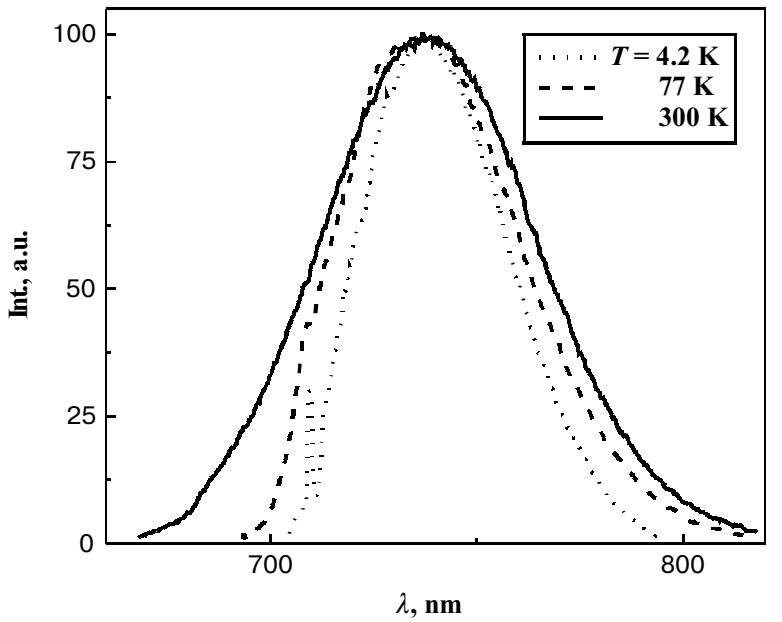

Fig. 5. Luminescence spectra of the $\mathrm{KAlP}_{2} \mathrm{O}_{7}(\mathrm{Cr})$ crystals $(C(\mathrm{Cr})=$ $=0.02$ mass \%) at $\lambda_{e x}=632.8 \mathrm{~nm} ; T=4.2,77$ and $300 \mathrm{~K}$.

rity chromium ions incorporation into lattice of the $\mathrm{KAlP}_{2} \mathrm{O}_{7}$ phosphate crystals and spectroscopy of chromium ions in crystals are necessary to discuss an emission of impurity chromium luminescence centers in investigated compounds.

Three-dimensional frameworks of corner-sharing $\mathrm{AlO}_{6}$ octahedrons and the $\mathrm{P}_{2} \mathrm{O}_{7}$ diphosphate groups is a base of the structure of the $\mathrm{KAlP}_{2} \mathrm{O}_{7}$ crystal of monoclinic singonia. Each of octahedron is bonded with five diphosphate groups; one of them shares two vertexes with the same $\mathrm{AlO}_{6}$ octahedron, others four links different $\mathrm{AlO}_{6}$ octahedrons. Average Al-O distance is equal 1.89 [ [7]. Potassium, aluminum and phosphor ions of these compounds are positive charged and have $+1,+3$ and +5 charges respectively. We have to assume the chromium ions location $\mathrm{Cr} 3+$ on the aluminum positions in the $\mathrm{AlO}_{6}$ octahedrons are the most optimal for these ions if we take into consideration electro neutrality principle and the ratio of the radii for mentioned impurity and lattice ions. Really, the aluminum and chromium ions charges are equal $-3+$ and their radii are 0.63 and $0.57 \AA$ respectively (the radii ratio is $R\left(\mathrm{Cr}^{3+}\right) / R\left(\mathrm{Al}^{+}\right)=1.1(1)$ ), that is suitable for aluminum ions replacements by $\mathrm{Cr} 3+$ ions in the lattice of the $\mathrm{KAlP}_{2} \mathrm{O}_{7}$ crystals.

The ratio of the $\mathrm{Cr}^{3+}$ - ion radius and potassium ions radius $R\left(\mathrm{Cr}^{3+}\right) / R\left(\mathrm{~K}^{+}\right)=0.47$. The $\mathrm{K}+$ ions are located in large cavities, and can be substituted by the smaller $\mathrm{Cr}^{3+}$ - ion, but, in this case a complex compensation of an effective charge +2 needs to form vacancies of two neighbor potassium ions. The ratio of the $\mathrm{Cr}^{3+}$ - ion radius and phosphorus $\mathrm{P}^{5+}$ ions radius is and $R\left(\mathrm{Cr}^{3+}\right) / R(\mathrm{P} 5+)=1.8$ prevents the incorporation of chromium $\mathrm{Cr}^{+}$- ions into the positions of phosphorus ions.

At the same time, it should be considered that there are many natural and synthesized compounds where chromium is in tetrahedral oxide surrounding and possesses charge equal $+6[8]$. The ionic radius of $\mathrm{Cr}^{6+}$ and $\mathrm{P}^{5+}$ are practically the same, the effective charge +1 , formed af- ter such replacement can be compensated by one potassium vacancy.

Real geometry tetrahedral groups don't exist in the ideal $\mathrm{KAlP}_{2} \mathrm{O}_{7}$ crystals, but the $\mathrm{P}_{2} \mathrm{O}_{7}$ diphosphates groups of the crystals can be regarded as formed by two $\mathrm{PO}_{4}$ tetrahedral groups which possess one common oxygen ion. Phosphorus ions in these groups are coordinated by four oxygen ions. That is why, the $\mathrm{O}_{3}-\mathrm{P}-\mathrm{O}$ part of diphosphates group can be consider as deformed in geometry and in charge tetrahedron $\mathrm{PO}_{4}$. Relation between the impurity $\mathrm{Cr}^{6+}$ chromium ion and the $\mathrm{P}^{5+}$ - phosphorus ions radii is equal $R\left(\mathrm{Cr}^{6+}\right) / R\left(\mathrm{P}^{5+}\right)=1$ that is suitable to realize the variant of displacement of phosphorus ion by the impurity of the $\mathrm{Cr}^{6+}$ ions.

So, when we discuss the variants of chromium ions incorporation into the $\mathrm{KAlP}_{2} \mathrm{O}_{7}$ crystal lattice the possibilities to locate themselves like to both the $\mathrm{Cr}^{3+}$ on the position of the aluminum ions and the $\mathrm{Cr}^{6+}$ on the position of phosphorus ions in the composition of diphosphate groups. Last case is similar to formation of $\mathrm{O}_{3}-\mathrm{P}-(\mathrm{O}-$ $\left.\mathrm{Cr}-\mathrm{O}_{3}\right)$ groups. Surely, the electronic structure of $(\mathrm{O}-$ $\mathrm{Cr}-\mathrm{O}_{3}$ ) fragment of mentioned group is far from the ideal free tetrahedron $\mathrm{CrO}_{4}{ }^{2-}$ one, but on the other hand, as was shown recently, just the deformed $\mathrm{CrO}_{4}$ tetrahedrons are the origins of photo- and X-ray luminescence of the oxide crystals those contain $\mathrm{CrO}_{4}{ }^{2-}$ anion groups.

Indeed, the comparison between luminescence and excitation characteristics, obtained by us for the $\mathrm{KAlP}_{2} \mathrm{O}_{7}(\mathrm{Cr})$ crystals and characteristics of $\mathrm{CrO}_{4}{ }^{2-}$ molecular groups, which are incorporated in various matrixes (alkali-halide crystals, crystals and glasses of alkali and alkali-earth elements $[9,10])$ or they are components of the complex oxide crystals (the alkali chromate crystals $[11,12]$ shows that the long wave components of the "green-orange" luminescence could be regarded as originated from the $\mathrm{CrO}_{4}{ }^{2-}$-groups emission. Accordingly to the same data the $\mathrm{CrO}_{4}{ }^{2-}$ chromate groups could be the base of the complex luminescence centers and the emission of which is characterized with spectral bands those place in the region $600-800 \mathrm{~nm}$. Mentioned complex luminescence centers are formed preferably in the crystals which contain some defects, f.e., oxygen vacancies, positively charged impurities and $\mathrm{F}^{-}$centers too.

As for spectroscopic characteristics of $\mathrm{Cr}^{3+}$ ions, their luminescence in solid state can reveal like to wide band of "red" luminescence and/or two narrow, so called $R$ lines. The last, if they are, have to lye on the short wavelength side of the "red" luminescence band. The maxima of mentioned bands and lines lye in the region from 670 to $800 \mathrm{~nm}$, that determines by the force of crystal field (by type of crystal matrix) where the $\mathrm{Cr}^{3+}$ ion is situated [2-5]. It is well known, that $R$-lines caused by ${ }^{2} \mathrm{E} \rightarrow{ }^{4} \mathrm{~A}_{2}$ radiation transitions, while "red" luminescence band is identified as corresponding to radiation transition ${ }^{4} \mathrm{~T}_{2} \rightarrow{ }^{4} \mathrm{~A}_{2}$.

The results of the experimental investigation the both of undoped "pure" $\mathrm{KAlP}_{2} \mathrm{O}_{7}$ and doped with chromium $\mathrm{KAlP}_{2} \mathrm{O}_{7}(\mathrm{Cr})$ crystals could have get the next explanations taking into consideration the description of the possible forms of chromium ions existing in the lattice of the 


\section{O.V. Gomenyuk et al.: Luminescence properties of $\mathrm{KAIP}_{2} \mathrm{O}_{7}$ crystals doped with ...}

$\mathrm{KAlP}_{2} \mathrm{O}_{7}$ crystals and possible manifestations of their luminescent properties in some solid state matrixes.

"Green-orange" emission of the deformed $\mathrm{CrO}_{4}{ }^{2-}$ molecular groups in doped with the chromium ions $\mathrm{KAlP}_{2} \mathrm{O}_{7}(\mathrm{Cr})$ crystals is added to the own "blue-green" emission of the undoped crystals. Luminescence of complex centers formed on the base of the same molecular groups can originate "red" luminescence of doped crystals. But, if we take into account the next:

- the shape of this band is differed from its shape for the observed recently complex $\mathrm{CrO}_{4}{ }^{2-}$ centers,

- the small probability of these centers formation if compare with possibility to form centers based on the $\mathrm{Cr}^{3+}$ - ions,

- manifestation of the lines which can be identify as $R$ lines of the $\mathrm{Cr}^{3+}$-ions luminescence, we should do the conclusion that $\mathrm{KAlP}_{2} \mathrm{O}_{7}(\mathrm{Cr})$ crystals "red" luminescence is caused by radiation transition in the $\mathrm{Cr}^{3+}$ ions.

Described imaginations concerning complex superposition structure of luminescence spectra (host matrix luminescence + emission of the impurity $\mathrm{Cr}^{3+}+$ emission of the centers formed on the base of the $\mathrm{CrO}_{4}{ }^{2-}$ molecular groups) give the possibility to explain the changes those take place in the luminescence spectra dependently on temperature and wavelength of the exiting light. Surely, according to the literature data short wave length excitation in the region of the excitation band I (particularly at $\lambda_{e x}=337.1 \mathrm{~nm}$ ) initiates the own emission of the matrix and the emission of the deformed $\mathrm{CrO}_{4}{ }^{2-}$ molecular groups - together they compose give "blue-green" luminescence band [9-12]. That is why, the last contain of a set of the components (Fig. 1, 2). The light from the diapason of the excitation band II is unavailable to excite own matrix emission, so only the bands of the impurity luminescence are observed. They caused by the emission of the deformed $\mathrm{CrO}_{4}{ }^{2-}$ molecular groups, of the complex centers formed on their base and by the emission of the $\mathrm{Cr}^{3+}$ ions. Changes of the shapes, relative intensities and maxima positions (Fig. 4) are related with changing of the contribution one or other centers to the integral spectra dependently on the exciting light wavelength.

Temperature changes which take place at short (Fig. 1) and long (Fig. 2) wave length excitation possess a different nature. It is should consider that temperature increasing at short wavelength excitation (particularly at $\lambda_{\text {ex }}=337.1 \mathrm{~nm}$ ) initiates the processes of excitation energy passing from the matrix to the $\mathrm{Cr}^{3+}$-ions, that leads to the rise of intensities of the long wave length components of the "green-orange" luminescence band and also to the rise of the "red" luminescence band intensity as well (Fig. 1). Temperature changes of luminescence characteristics occurring at the most longer wave length excitation in the region of band I (particularly at $\lambda_{\text {ex }}=632.8 \mathrm{~nm}$ ), when only the impurity $\mathrm{Cr}^{3+}$ ions can be excited, are explained by the dependence on the temperature of the electron-vibronic interaction degree at electronic transition ${ }^{4} \mathrm{~T}_{2} \rightarrow{ }^{4} \mathrm{~A}_{2}$ which causes the "red" luminescence band. If temperature decreases, electronvibronic interaction degree is lowered, that leads to nar- rowing of the "red" band. As result, recently masked details of spectra get manifested; especially narrow lines of the ${ }^{2} \mathrm{E} \rightarrow{ }^{4} \mathrm{~A}_{2}$ transitions become observable [13].

\section{Conclusions}

Some conclusions can be made on the base of analysis of both literature data on spectroscopy of impurity chromium ions located in various crystalline matrixes and experimental results obtained in the present work.

Luminescence of the $\mathrm{KAlP}_{2} \mathrm{O}_{7}$ crystals doped with chromium ions is a superposition of own emission of the matrix and an emission of the luminescence centers formed by the impurity chromium ions.

The "green-orange" luminescence band (diapason $450-690 \mathrm{~nm}$ ) is a superposition of the own luminescence of matrix (short wave length components at 475, 505 and $525 \mathrm{~nm}$ ) and the emission of the distorted $\mathrm{CrO}_{4}{ }^{2-}$ anions, which cause the luminescence spectra components with peak positions near 550, 600 and $650 \mathrm{~nm}$.

The "red" luminescence band with the maximum near $745 \mathrm{~nm}$ as well as narrow lines at 708 and $725 \mathrm{~nm}$ on its short wave length wing is initiated by the $\mathrm{Cr}^{3+}$ ions those are placed in the octahedron oxide surrounding and substitute $\mathrm{Al}^{3+}$ ions of the crystal lattice.

\section{References}

1. A.A. Kaminskii, Laser crystals, "Nauka", Moscow, 1975 (in Russian).

2. A.O. Matkovskii, Materials for quantum electronics, "LigaPress", Lviv, 2000 (in Ukrainian).

3. A.P. Elyseev, A.M. Yurkin, E.M. Fedorova, and E.G. Samojlova, Spectroscopy of the $\mathrm{Cr}^{3+}$ in the center symmetry position in alexandrite // J. Appl. Spectroscopy (Minsk), 44, pp. 491-494 (1986).

4. M.R. Sirtlanov, Nonradiative relaxation of trivalent chromium in glass // Journal of Luminescence, 59, pp. 101-111 (1994).

5. U. Hommerich, H. Eilers, W.M. Yen, J.S. Hayden, and M.K.Aston, Near infrared emission at $1.35 \mathrm{~m}$ in $\mathrm{Cr}$ doped glass // Journal of Luminescence, 60\&61, pp. 119-122 (1994).

6. I. Vergara, J. Sole Garsia, M.A. Hoyos, and T. Calderon, Fluorescence properties of $\mathrm{Cr} 3+$ in natural eosphorite crystal // Solid state Communications, 76, pp. 289-292 (1979).

7. E.A. Genkyna // J. Structural Chem., 6, pp. 92-96 (1990) (in Russian).

8. V.A. Ryabin, M.V. Kireeva, N.V. Berg et al., Inorganic chromium compounds, "Himiya", Leningrad, 1981 (in Russian).

9. M.U. Belyi, Yu.D. Glynka, I.Ya. Kushnirenko, Luminescence of the chromate complexes $\left(\mathrm{CrO}_{4}^{2-}\right)$ in the $\mathrm{CsBr}$ crystals // Dopovydi NAS of Ukraine. Ser."A", 4, pp. 41-44, 1988 (in Russian).

10. M.U. Belij, T.V. Krak, S.G. Nedelko, and Yu.M.Titov, Synthesis and luminescence investigations of akermanite type ceramics // Proc. of the 5th European Conf. On Advanced Materials, 3, pp. 633-636, Maastricht, 1997.

11. M.U. Belyi, S.G. Nedilko, O.V. Chukova, Luminescent properties of alkali chromate crystals // J. Appl. Spectroscopy (Minsk), 63, pp. 241-250 (1995).

12. G.A.M. Dalhoeven and G. Blasse On the luminescence of the Chromate $\left(\mathrm{CrO}_{4}^{2-}\right)$ Complex // Chem Phys. Let., 76, pp. 27-29, 1980.

13. D.T. Sviridov, R.K. Sviridova, Yu.F. Smyrnov, Optical spectra of the transition ions in crystals, "Nauka", Moscow, 1976 (in Russian). 